\title{
Uniform Application of Laws in the Context of Post-Classical Law
}

\author{
Igor M.Alekseev* \\ Russian State University of Justice \\ St. Petersburg, Russian Federation
}

Received 18.05.2020, received in revised form 20.08.2021, accepted 14.09.2021

\begin{abstract}
The article reveals the impotence of classical legal theories to explain the inconsistency of the practice of applying laws. The legal dogma is subjected to the phenomenological analysis. Moreover, its inability to overcome the conventions of pure jurism is shown. From the position of postclassical jurisprudence, the theory of natural law is criticized. The necessity of refusing to contrast natural and positive law is substantiated. The communicative concept of law, its cognitive value and role in ensuring a uniform application of laws are considered. The criticism of integrative legal theories is evaluated from the perspective of the functionality of law in the form of resolving social conflicts. The approach that reduces legal theory to a method of resolving conflicts is called into question. The negative influence of the dichotomy of positive and natural law is argued, both on the uniform application of laws and on the rule of law in general. From the point of view of the functionality of law, the correlation of its material and procedural branches is revealed. As a result, a hypothesis is formulated that the main direction of the development of legal science is the creation of integrative law that can combine various legal concepts, which will allow us to build a rigid legal dogma based on unified methodological foundations and remove contradictions between legal theories in resolving social conflicts.
\end{abstract}

Keywords: social conflict, functionality of law, legal positivism, legal dogma, natural law, communicative theory of law, phenomenological analysis, postclassical jurisprudence, uniform application of laws.

Research area: law.

Citation: Alekseev, I.M. (2021). Uniform application of laws in the context of post-classical law. J. Sib. Fed. Univ. Humanit. soc. sci., 14(11), 1596-1605. DOI: 10.17516/1997-1370-0842

(C) Siberian Federal University. All rights reserved

* Corresponding author E-mail address: kaspar555@mail.ru 


\title{
Единообразное применение законов
}

\section{в контексте постклассического правоведения}

\author{
И.М.Алексеев \\ Российский государственньий университет правосудия \\ Российская Федерачия, Санкт-Петербург
}

\begin{abstract}
Аннотация. В статье выявляется бессилие классических правовых теорий объяснить противоречивость практики применения законов. Феноменологическому анализу подвергнута юридическая догматика. Более того, показана ее неспособность преодолеть условности чистого юридизма. С позиции постклассического правоведения критикуется теория естественного права. Обосновывается необходимость отказа от противопоставления естественного и позитивного права. Рассматривается коммуникативная концепция права, ее познавательная ценность и роль в обеспечении единообразного применения законов. Оценивается критика интегративных правовых теорий с позиции функциональности права в виде разрешения социальных конфликтов. Под сомнение ставится подход, сводящий правовую теорию к методу разрешения конфликтов. Аргументируется негативное влияние дихотомии позитивного и естественного права как на единообразное применение законов, так и на режим законности в целом. С точки зрения функциональности права раскрывается соотношение его материальных и процессуальных отраслей. В результате формулируется гипотеза, что основным направлением развития правовой науки является создание интегративного права, способного объединить различные правовые концепции, что позволит выстроить жесткую, основанную на единых методологических основах юридическую догматику и снять возникающие между правовыми теориями противоречия при разрешении социальных конфликтов.
\end{abstract}

Ключевые слова: социальный конфликт, функциональность права, юридический позитивизм, юридическая догматика, естественное право, коммуникативная теория права, феноменологический анализ, постклассическое правоведение, единообразное применение законов.

Научная специальность: 12.00 .00 - юриспруденция.

\section{Введение в проблему исследования}

Проблемы, связанные с единообразным применением законов на территории РФ, остаются неразрешенными до сих пор. На важность обеспечения единообразной судебной практики 12 февраля 2020 г. в своем докладе к совещанию судей судов общей юрисдикции и арбитражных судов Российской Федерации обратил внимание Председатель Верховного Суда РФ Вячеслав Михайлович Лебедев. Он отметил, что в 2019 г. Верховным Судом РФ было принято 16 постановлений Пленума, которые содержат более 600 правовых позиций по вопросам правоприменения (Lebedev, 2020). Однако, несмотря на бурную деятельность Верховного Суда РФ, анализ судебной практики позволяет утверждать о ее противоречивости (Kovtun, 2019: 132-136).

В этой связи отметим, что важной гарантией единства судебной практики является уголовно-процессуальная форма. Жесткая, иерархичная, согласованная, понятная процессуальная форма призвана обеспечить единообразную практику ее применения. Однако изучение проблем уголовно-процессуальной формы с позиций классических правовых теорий не по- 
зволило нам объяснить создавшееся положение. С точки зрения позитивизма есть норма закона, смысл, заложенный в нее законодателем, и правоприменитель, который этот смысл извлекает из нормы. Таким образом, противоречия на практике объясняются, по сути, либо некомпетентностью правоприменителя, либо несовершенством закона, допускающего различное его толкование.

\section{Концептологические}

\section{основания исследования}

Юридическая догматика (на которой основан юридический позитивизм) может исправлять только несовершенство закона. Правоприменитель остается за ее пределами. Догматик, выявив противоречия, пробелы и иные изъяны в законе, устраняет их путем внесения изменений в действующее законодательство, на чем и стоит современная юриспруденция. Например, при написании диссертаций по юридическим наукам, как правило, все сводится к анализу теории и практики применения определенного института, обобщению выявленных недостатков и подготовке предложений по изменению действующего законодательства, эти недостатки устраняющих. Все это выдается за развитие правовой науки. Однако это, если так можно выразиться, экстенсивный путь развития науки, не позволяющий выйти на границы условностей, выработанных юридической догматикой.

Так, Н.Н. Алексеев, критикуя юридическую догматику, отмечал: «Такие исследования практически весьма плодотворны, но порок условности, неизбежно связанный с ними, побуждает исследователя к исканию каких-то «действительных», «естественных», «существенных» определений права. Дело идет здесь не об искании «конечных причин», не о бесплодных метафизических стремлениях, - дело идет об освобождении от полной юридической беспринципности, от крайнего релятивизма» (Alekseev, 1998: 24).

Выход из условности чистого юридизма был указан теорией естественного права. Понятие «естественное право» родилось по противопоставлению с правом положительным, установленным, явившимся в результате человеческого изобретения; оно символ всего в правовом смысле истинного, соответствующего вечным законам справедливости (Alekseev, 1998: 29). Юснатурализм впервые обозначил проблему ценностной легитимации права, верно установив неразрывную связь между правом и моралью, религией, справедливостью и т. д., однако неверно ее абсолютизировал.

По справедливому замечанию А. В. Полякова, сама концепция естественного права как права, отличного от позитивного, содержит неустранимые противоречия, для разрешения которых требуется или отказаться от самой идеи естественного права в пользу естественного правосознания (т. е. совокупности представлений о должном праве), или признать естественным правом особую разновидность права позитивного, что также устранит естественное право. Выход из создавшегося теоретического тупика ученый видит только один - отказ от противопоставления естественного и позитивного права, так как всякое право, по его мнению, по своей природе позитивно (Polyakov, 2000: 8-10). Действительно, юснатурализм выполнил свою историческую миссию и в настоящее время является не более чем представлением о должном праве. Современная теория права не должна возрождать ложный дуализм естественного и позитивного права, ее задача - работать над концепцией, которая объясняла бы право как многообразный, но единый феномен, существующий на разных социальных уровнях и в разных ипостасях (Polyakov, 2000: 6).

Для постклассических теорий в целом нетипичны любые противопоставления. Отсюда проистекает стремление сторонников постклассического стиля в теории права к синтезу позитивистских и непозитивистских типов понимания (Varlamova, 2014: 236). Так, А.В. Поляков полагает, что проблему их противостояния можно разрешить «с позиций постклассической науки, обосновав некую «третью теорию» в рамках новой гносеологии и онтологии, 
которая снимает противоречия между естественным и позитивным правом, «примиряя» их между собой» (Polyakov, 2008: 10).

В качестве этой «третьей теории» ученый обосновал коммуникативную теорию права (Polyakov, 2002). По убеждению Полякова, право есть часть жизненного мира человека, система рекурсивных коммуникаций, и оно не может быть сведено ни к законам, ни к норме, ни к идеалам, ни к отношениям, ни к психике человека, взятым в качестве отдельных смысловых центров понятия права. Взаимодействующие правовые субъекты (в постнеклассической науке - субъекты правовой коммуникации) становятся тем связующим звеном, которое соединяет нормативистский этатизм с юснатурализмом, а позже - с социологическим и психологическим правопониманием (Polyakov, 2006: 28-29).

При этом коммуникативная концепция права по своей сути является позитивистской. Во-первых, автор сам пишет, что «всякое право по своей природе позитивно». Во-вторых, ученый определяет правовую коммуникацию как «правовое взаимодействие между субъектами, возникающее на основе социальной интерпретации правовых текстов как предоставляющих им коррелятивные правомочия и правообязанности, реализуемые в правовом поведении» (Polyakov, 2002: 9-10). Вне позитивной нормы права не существует.

При этом упор все же делается на коммуникацию между людьми, в ходе которой право легитимируется. По нашему мнению, коммуникативная теория права, как, собственно, и любая другая правовая теория, не может обеспечить единство правоприменительной практики. Однако она в состоянии объяснить причины, по которым невозможно единообразное применение законов на всей территории страны, а значит, позволит воздействовать на эти причины, прогнозировать отклонения в практике применения норм в том или ином регионе.

Причины познавательной ценности коммуникативной теории права кроются в том, что она основана на достижениях современной феноменологии и герменевти- ки, постулирующих тот факт, что познание вплетено в историческую практику и не может быть полностью свободным от предрассудков, воспринятых в процессе воспитания в конкретной языковой среде. При этом необходимо отметить, что предрассудок в герменевтике утрачивает негативный оттенок, придаваемый им материалистами, которые призывали преодолевать последние на пути познания истины. Традиция, в которой воспитывается человек, - это тот смысловой универсум, который включает в себя наши представления о мире (Gaponov, 2016: 24). Выйти за их пределы представляется задачей, практически невыполнимой для исследователя. Общество не является объектом, противостоящим познающему субъекту и по отношению к которому возможна внешняя позиция наблюдателя, оно выступает универсальной средой нашего познания.

Указанные методологические основания позволяют по-новому взглянуть на материальные основания права, преодолеть его условность, объяснить противоречия в практике его применения. Однако постклассические теории, в том числе и коммуникативная теория права, были подвергнуты критике со стороны представителей классических правовых теорий.

Например, Л.В. Головко пишет, что «коммуникативная теория права при всей своей общенаучной перспективности не способна ответить ни на один вопрос, стоящий в сугубо правовой плоскости, в силу чего, вопреки известным заявлениям о «постклассической эре», мы видим, что любые судебные решения - от мирового судьи до ЕСПЧ - по-прежнему базируются либо на позитивистской (чаще), либо на естественно-правовой (реже) логике. Никакой «коммуникативной» аргументации мы в них не находим» (Golovko, 2016: 101).

\section{Постановка проблемы}

Действительно, ни один спор интегративно, коммуникативно, основываясь на психологической или социологической правых теориях разрешить нельзя. Поэ- 
тому с утверждением Л.В. Головко невозможно не согласиться. Однако возникает вопрос, как можно разрешить спор с помощью позитивизма или юснатурализма, в чем заключаются разработанные ими методы разрешения социальных конфликтов. Так, ученый пишет: «Учитывая функциональную нагрузку права, очевидным является, что любая фундаментальная теория права представляет собой метод разрешения правовых конфликтов, причем сами теории должны быть в каждом конкретном практическом случае взаимоисключающими, поскольку отдельный конфликт (спор) может быть решен только с помощью одного из методов. Выбор метода здесь предопределяет решение. Именно так происходит, например, с двумя величайшими из существующих методов: 1) позитивистским; 2) естественно-правовым. Судья может решить спор, опираясь либо на позитивистскую логику, либо на логику естественно-правовую, причем его выбор имеет значение только в ситуации, когда между двумя этими методами в свою очередь существует конфликт: одна сторона права исходя из действующих позитивных норм, а другая - если оперировать фундаментальными принципами права. Когда же между принципами и позитивными нормами противоречия нет, то и выбор метода значения не имеет» (Golovko, 2016: 96).

Как видим, позитивистский метод основан на применении действующих правовых норм, а естественно-правовой метод использует фундаментальные принципы права. На первый взгляд, вполне простая и понятная мысль. Однако если мы говорим о конкуренции между методами, то необходимо признать, что субъект, разрешающий спор, должен иметь право выбора между этими методами. При этом вполне очевидно, что выбор между указанными методами отсутствует. Если нормы позитивного права вступают в противоречие с фундаментальными принципами, то судья обязан принять решение исходя из этих принципов. Так, в ст. 18 Конституции РФ указано: «Права и свободы человека и гражданина являются непосредственно действующи- ми. Они определяют смысл, содержание и применение законов». Как видим идеи, заложенные естественно-правовой теорией права, нашли отражение в праве позитивном. Юридическая догматика «поглотила» естественное право, поставив его на первое место в иерархии источников права. Отсюда вопрос, в чем заключается противопоставление позитивного и естественно-правового методов разрешения социальных конфликтов. Мы не смогли на него ответить.

\section{Обсуждение \\ 1. Конкуренция позитивистского \\ и естественно-правового методов \\ разрешения социальных конфликтов}

При этом конкуренция указанных методов объясняет противоречивую практику применения закона, но не позволяет влиять на нее. Так, если все же представить, что конкуренция между этими методами есть, то юридических категорий, выработанных позитивизмом и юснатурализмом, не достаточно, чтобы ответить на вопросы, возникающие в ходе их конкуренции. Например, если мы говорим, что позитивизм как метод разрешения конфликтов занимает господствующее положение на нижних уровнях судебной системы, а естественно-правовой в высших судебных инстанциях (Golovko, 2016: 104), то непонятно, с чем это связано. Почему один суд в конкретном споре использует позитивистскую логику, а другой - естественно-правовую? Или, например, почему гражданин должен пройти все судебные инстанции, чтобы его дело было рассмотрено с естественно-правовых позиций? Как быть другой стороне, последовательно выигравшей несколько процессов, основываясь на букве закона и проиграв последний процесс в суде высшей инстанции ввиду того, что было обеспечено право другой стороны, данное от рождения, но о котором «предпочли забыть» все нижестоящие судебные инстанции? Более того, почему суды одного уровня могут использовать разные методы разрешения юридических споров? От чего это зависит: от образования, воспитания, погоды или чего-то еще? 
Например, в соответствии с ч. 2 ст. 256 УПК РФ определение суда о возвращении уголовного дела прокурору или об избрании, изменении или отмене меры пресечения в отношении подсудимого выносится в совещательной комнате и излагается в виде отдельного процессуального документа. В свою очередь Верховный Суд РФ при разрешении конкретного дела указал, что суду не обязательно удаляться в совещательную комнату и выносить отдельный документ, чтобы отклонить ходатайство о возвращении уголовного дела прокурору или об изменении меры пресечения по делу (Appeal determination of the Supreme Court of the Russian Federation, 2016).

При вынесении этого решения судья, скорее всего, исходил из логики естественно-правовой. То есть, несмотря на нарушение уголовно-процессуальной нормы, права и свободы, данные человеку, нарушены не были, а значит, нет и оснований для пересмотра уголовного дела. Если мы признаем возможность конкуренции методов разрешения конфликтов в каждом конкретном споре, то где гарантия, что следующее аналогичное дело не рассмотрит убежденный позитивист? Как в таком случае быть правоприменителю при разрешении юридических споров, опираться на неотчуждаемые права человека, закон или эталонные судебные решения, производимые Верховным Судом РФ, а как быть, если они противоречат друг другу? На все эти вопросы основываясь на конкуренции методов выработанных позитивизмом и юснатурализмом, ответить не представляется возможным.

По нашему мнению, такое противопоставление методов разрешения конфликтов исключительно негативно влияет на единообразное применение законов и в общем на режим законности в стране. Ведь если мы признаем, что обе стороны правы, но только исходя из разных теоретико-правовых установок, то суд, принимая итоговое решение, выбрав тот или иной метод, по сути, не разрешит конфликт. Проигравшая сторона будет считать решение суда несправедливым, и, что самое главное, эта несправедливость всегда будет иметь серьезную теоретикометодологическую основу.

Именно поэтому нужна новая теория права, объединяющая позитивное и естественное право и позволяющая выстроить прочный фундамент юридической догматики для разрешения социальных конфликтов. При этом правовая теория не может ждать, пока материальный мир придет в согласие с миром юридических установлений, она должна объяснять существующие между ними противоречия, чтобы посредством юридических средств их разрешать.

\section{2. Соблюдение правовых предписаний с позиции функциональности права}

Абсолютизация методологического ракурса к праву как форме разрешения социальных конфликтов в целом приводит нас к довольно-таки сомнительным выводам. Например, если лицо совершило преступление, однако потерпевший не стал обращаться в правоохранительные органы, а примирился с лицом, преступление совершившим, не используя для этого правовые механизмы, или по какой-то причине преступление оказалось латентным. Соответственно, следуя методологическим установкам, понимающим право как форму решения конфликтов, а правовые теории только те, которые можно использовать как метод разрешения конфликтов, можно сделать вывод о том, что указанные общественные отношения оказались «за бортом» права.

В подтверждение этому можно привести следующие умозаключения Л.В. Головко: если запрет не нарушен, то причины поведения вообще не имеют значения. Если он нарушен, но никто этого не увидел, причины опять-таки de facto значения иметь не будут, поскольку правонарушение останется латентным. Но вот если правонарушение окажется установленным уполномоченным лицом (полицейским и т. п.), то все зависит от согласия или несогласия лица со штрафом, который он вправе уплатить или оспорить. Добровольная уплата, конечно, также имеет все необходимые правовые последствия и легко описывается в право- 
вых понятиях (правонарушение, санкция, исполнение и т. п.), но здесь правоприменение остается, скажем так, на элементарном уровне. Сложным оно станет в случае возникновения спора, связанного с отказом лица платить штраф, и дальнейшей процессуализацией данного спора. Она приведет к появлению подлинно правовой логики, поскольку конфликт (спор) надо разрешить (Golovko, 2016: 99).

Как видно из указанных выше умозаключений, изучение права как функционального механизма, по сути, затрагивает только один его аспект - правоприменение. В свою очередь соблюдение правовых предписаний, позволяющее говорить о реализации положений закона, остается за рамками правовых категорий, что, по нашему мнению, ведет к безосновательному «обеднению» правовой науки. Так, К.В. Муравьев совершенно справедливо пишет, что, устанавливая, какое общественное деяние является преступлением, государство ставит под уголовно-правовую охрану общественные отношения и одновременно определяет необходимый образ действий их субъектов, следование которому позволяет исключить совершение противоправного деяния. Ситуация общественно опасного деяния свидетельствует о том, что добровольной реализации уголовного закона в форме соблюдения не произошло. Тогда реализовать уголовный закон возможно только в форме исполнения посредством применения норм уголовного закона (Murav’ev, 2017: 21-26).

Например, лицо решило совершить преступление, однако отказалось от его совершения, вспомнив, что есть уголовный закон, и испытав при этом определенные психологические эмоции. Очевидно, что здесь уголовное право, выполняя охранительную функцию, достигло своей цели и было реализовано в форме соблюдения, правоприменительная деятельность как специфическая форма реализации правовых норм не понадобилась.

Касательно значения причин поведения отметим, несмотря на то, что с формальноюридической точки зрения поведение считается правомерным независимо от того, по каким мотивам человек не нарушает правовых предписаний, не выходит за рамки дозволенного законом. Но социальная характеристика правомерного поведения не может быть дана без учета его мотивации. Тот же юридический позитивизм, по крайней мере в марксистско-ленинской его трактовке, выходил за рамки юридической догматики, изучая в правовом поле виды правомерного поведения граждан (Alekseev, Dyuryagin, Korel'skiy, Rusinov, Cherdantsev, 1979: 332-334).

Таким образом, поддерживая отношение к праву как форме разрешения социальных конфликтов, отметим, что изучение причин соблюдения правовых предписаний как способа реализации правовых норм имеет такой же правовой характер, как, собственно, и анализ юридико-догматических методов разрешения конкретных юридических споров (конфликтов). По этой причине теория права не может сводиться к поиску методов разрешения конфликтов. Что же касается разрешения конкретных дел, то это дело юридической догматики, через которую теории права действуют не непосредственно, а опосредованно. По этой же причине ни одна из правовых теорий не может «приватизировать» юридическую догматику. Как мы уже указывали, все право позитивно.

\section{3. Соотночение материального и процессуального права}

Мы не можем согласиться с мнением Л.В. Головко касательно места материальных отраслей права в системе правовых инструментов разрешения конфликтов. Так, автор указывает, что «в любой социальной системе (в самом широком смысле) количество конфликтов уходит в бесконечность, что и предопределяет развитие правовых инструментов их разрешения, причем не только процессуальных, но и на соответствующем этапе эволюции права материально-правовых, когда казуистические методы a posteriori начинают вытесняться абстрактным правовым регулированием a priori (чтобы в последующем разрешить гипотетический конфликт, тре- 
буется зафиксировать права и обязанности, запреты и дозволения и т. п.)» (Golovko, 2016: 94).

В таком разделении процессуальных и материальных отраслей права в деле разрешения конфликтов мы видим противоречие, заключающееся в том, что ученый изначально говорит, что если стороны конфликта нашли другие, неправовые способы разрешения конфликта, то в этом нет ничего правового. Теперь же он утверждает, что на определенном этапе эволюции права главенствующую роль начинает играть абстрактное правовое регулирование, заключающееся в фиксации прав и обязанностей, запретов и дозволений, направленных на разрешение гипотетических конфликтов. Поскольку Л.В. Головко пишет о вblтеснении (курсив наш. - И.А.) юридических способов разрешения конфликтов абстрактным превентивным правовым регулированием, то можно сделать вывод, что с развитием права реализация правовых норм в большей степени будет осуществляться в форме соблюдения.

Мы не может согласиться с таким разделением процессуальных и материальных инструментов разрешения конфликтов. По нашему мнению, материальное право является правовым средством институциализации возможных социальных конфликтов, а право процессуальное формой их разрешения. Так, человек прибегает к процессуальным способам разрешения конфликта только в том случае, если знает, что государство в силу закона взяло на себя обязательство защищать право этого человека и в конечном итоге восстановить социальную справедливость путем применения наказания к лицу, это право нарушившему.

Например, потерпевший от незаконного проникновения в жилище обратится в правоохранительные органы только в том случае, если знает, что неприкосновенность жилища гарантирована Конституцией РФ и охраняется уголовным законом. В противном случае он будет искать другие, неинституциональные способы разрешения возникшего конфликта. При этом уголовное право также служит важным ограничителем в деле эскалации конфликта, когда потерпевший в выборе средств его разрешения вынужден оглядываться на уголовный закон, который заставляет его обратиться к правовым средствам разрешения конфликта. Причем соотношение это между правом процессуальным и материальным не меняется. Поэтому эволюцию права мы видим не в переходе от инструментов разрешения конфликтов a posteriori $\kappa$ правовому регулированию а priori, а в создании права, которое вытеснит иные способы разрешения конфликтов (здесь мы подразумеваем, конечно, только социально неприемлемые формы разрешения таких конфликтов, например, когда жертва преступления вместо того, чтобы обратиться в правоохранительные органы, устраивает самосуд или обращается к услугам третьих лиц в поисках справедливости и т. д.).

В нашем понимании это право интегративное, способное объединить различные правовые концепции, что позволит выстроить жесткую, основанную на единых методологических основах юридическую догматику и снять возникающие между правовыми теориями противоречия при разрешении социальных конфликтов. Это, конечно, не приведет к полному снятию проблем единообразия судебной практики, но нивелирует внешние, методологические противоречия.

\section{Заключение}

Таким образом, можно сделать следующие выводы:

1. Современная теория права не должна возрождать дуализм естественного и позитивного права, ее задача - работать над концепцией, которая объясняла бы право как многообразный, но единый феномен. Юснатурализм выполнил свою историческую миссию и в настоящее время является не более чем представлением о должном праве.

2. Коммуникативная теория права, как, собственно, и любая другая правовая теория, не может обеспечить единство правоприменительной практики. Одна- 
ко она в состоянии объяснить причины, по которым невозможно единообразное применение законов на всей территории страны, а значит, позволит воздействовать на эти причины, прогнозировать отклонения в практике применения норм в том или ином регионе.

3. Причины познавательной ценности коммуникативной теории права кроются в том, что она основана на достижениях современной феноменологии и герменевтики, постулирующих тот факт, что познание вплетено в историческую практику и не может быть полностью свободным от предрассудков, воспринятых в процессе воспитания в конкретной языковой среде. Указанные методологические основания позволяют по-новому взглянуть на материальные основания права, преодолеть его условность, объяснить противоречия в практике его применения.

4. Идеи, заложенные естественноправовой теорией права, нашли отражение в праве позитивном. Юридическая догматика «поглотила» естественное право, поставив его на первое место в иерархии источников права.

5. Противопоставление позитивистского и естественно-правового методов разрешения конфликтов исключительно негативно влияет на единообразное применение законов и в общем на режим законности в стране. Именно поэтому нужна новая теория права, объединяющая позитивное и естественное право и позволяющая выстроить прочный фундамент юридической догматики для разрешения социальных конфликтов.

6. Поддерживая точку зрения на право как на форму разрешения социальных конфликтов, считаем неверным сводить правовую теорию к поиску методов разрешения конкретных конфликтов. Разрешение конкретных конфликтов - дело юридической догматики, через которую теории права действуют не непосредственно, а опосредованно. По этой же причине ни одна из правовых теорий не может «приватизировать» юридическую догматику. Все право позитивно.

7. Материальное право является правовым средством институциализации возможных социальных конфликтов, а право процессуальное - формой их разрешения. При этом уголовное право также служит важным ограничителем в деле эскалации конфликта, когда потерпевший в выборе средств его разрешения вынужден оглядываться на уголовный закон, который заставляет его обратиться к правовым средствам разрешения конфликта.

8. Эволюцию права мы видим в создании права, которое вытеснит иные способы разрешения конфликтов. В нашем понимании это право интегративное, способное объединить различные правовые концепции, что позволит выстроить жесткую, основанную на единых методологических основах юридическую догматику и снять возникающие между правовыми теориями противоречия при разрешении социальных конфликтов.

\section{Список литературы / References}

Alekseev, N.N. (1998). Osnovy filosofii prava [Fundamentals of legal philosophy]. St. Petersburg, Iuridicheskii Institut, $217 \mathrm{p}$.

Alekseev, S.S., Dyuryagin, I.YA., Korel'skiy, V.M., Rusinov, R.K., Cherdantsev, A.F. (1979). Problemy teorii gosudarstva i prava [Problems of the theory of state and law]. Moscow, Yuridicheskaya literatura, $392 \mathrm{p}$.

Appeal determination of the Supreme Court of the Russian Federation (2016). No. 33-APU16-10. Available at: https://legalacts.ru/sud/apelliatsionnoe-opredelenie-verkhovnogo-suda-rf-ot-15092016-n-33apu16-10/ (accessed 10 May 2020).

Gaponov, A.S. (2016). Priroda sotsial'nogo poznaniya: evristicheskiy potentsial fenomenologogermenevticheskoy programmy [The nature of social cognition: the heuristic potential of the phenomenological-hermeneutic program: dissertation $\mathrm{PhD}$ of legal sciences]. Tomsk, $117 \mathrm{p}$. 
Golovko, L.V. (2016). Postsovetskaya teoriya prava: trudnosti pozitsionirovaniya v istoricheskom i sravnitel'no-pravovom kontekste [Post-Soviet theory of law: difficulties of positioning in a historical and comparative legal context], In Problemy postsovetskoy teorii i filosofii prava [Problems of post-Soviet theory and philosophy of law]. Moscow, 92-126.

Kovtun, N.N. (2019). Sudebnyy pretsedent - kak etalon primeneniya rossiyskogo ugolovnoprotsessual'nogo prava [Judicial precedent - as a standard of application of the Russian criminal procedural law], In Ugolovnoye sudoproizvodstvo Rossii: sovremennoye sostoyaniye i perspektivy razvitiya [Criminal proceedings in Russia: current status and development prospects]. Krasnodar, 132-136.

Lebedev, V.M. (2020). Report to the meeting of judges of the courts of general jurisdiction and arbitration courts of the Russian Federation. Available at: https://www.vsrf.ru/files/28759/ (accessed 10 May 2020).

Murav'ev, K.V. (2017). Optimizatsiya ugolovnogo protsessa kak formy primeneniya ugolovnogo zakona [Optimization of the criminal process as a form of application of the criminal law: dissertation doctor of legal sciences]. Omsk, 505 p.

Polyakov, A.V. (2000). Peterburgskaya shkola filosofii prava i zadachi sovremennogo pravovedeniya [Petersburg School of Philosophy of Law and the tasks of modern jurisprudence], Izvestiya vysshikh uchebnykh zavedeniy. Pravovedeniye [News of higher educational institutions. Jurisprudence], 2 (229), 4-23.

Polyakov, A.V. (2006). Postklassicheskoye pravovedeniye i ideya kommunikatsii [Postclassical jurisprudence and the idea of communication], Izvestiya vysshikh uchebnykh zavedeniy. Pravovedeniye [News of higher educational institutions. Jurisprudence], 2, 26-43.

Polyakov, A.V. (2008). Kommunikativnaya teoriya prava kak variant integral'nogo pravoponimaniya [Communicative theory of law as a variant of integral legal understanding], In Pravovyye idei i instituty $v$ istoriko-teoreticheskom diskurse ( $k$ 70-letiyu professora V. G. Grafskogo) [Legal ideas and institutions in the historical and theoretical discourse (on the 70th anniversary of professor V. G. Grafskogo)]. Moscow, $8-25$.

Polyakov, A.V. (2002). Kommunikativnaya kontseptsiya prava (genezis i teoretiko-pravovoye obosnovaniye) [The communicative concept of law (genesis and theoretical and legal justification): dissertation doctor of legal sciences]. St. Petersburg, 94 p.

Varlamova, N.V. (2014). Metodologicheskiye problemy sovremennoy yuridicheskoy nauki [Methodological issues modern legal science]. Aktual'nyye problemy filosofii prava i yuridicheskoy nauki v svyazi s kommunikativnoy teoriyey prava [Actual problems of the philosophy of law and legal science in connection with the communicative theory of law]. St. Petersburg, Izdatel'skiy dom «Alef-Press», 533 p. 